\title{
The Paradox of Declining Female Work Participation in an Era of Economic Growth
}

\author{
Sonalde Desai ${ }^{1,2} \cdot$ Omkar Joshi $^{1}$
}

Published online: 5 June 2019

(c) The Author(s) 2019

\begin{abstract}
The past three decades have seen the advent of major transformations in the Indian economy. The economy has achieved average growth rates of 5-9\%, education has risen sharply for both men and women, fertility rates have declined, and infrastructure facilities, particularly access to electricity, cooking gas and piped water, have improved. All these factors are expected to reduce the demand for women's time spent in domestic chores and increase their opportunities for paid work. Paradoxically, however, the National Sample Surveys document a substantial decline in women's work participation rates (WPRs), particularly for rural women. Optimistic interpretation of these trends suggests that increasing prosperity accounts for women's labour force withdrawal. For young women, rising school and college enrolment is incompatible with demands of the workforce. For both young and older women, rising prosperity allows for withdrawal from economic activities to focus on domestic duties. Pessimistic interpretations of these trends suggest that it is absence of suitable jobs rather than women's withdrawal from the labour force that accounts for declining female work participation. A third explanation focuses on increasing measurement errors in work participation data from the National Sample Surveys. This paper examines these diverse explanations using data from National Sample Surveys and India Human Development Surveys for 2004-2005 and 2011-2012 and finds that: (1) Decline in rural women's work participation recorded by National Sample Surveys may be overstated; (2) supply factors explain a relatively small proportion of the decline in women's work participation rates; (3) public policies such as improvement and transportation facilities and MGNREGS that enhance work opportunities for women are associated with increased participation by women in the work force.
\end{abstract}

Keywords Female Labour force participation - Decomposition analysis · Jobs · India

Sonalde Desai

sonalde.desai@gmail.com

1 University of Maryland, College Park, USA

2 National Council of Applied Economic Research, New Delhi, India 


\section{Introduction}

India's remarkably low levels of women's work participation are well recognized (Dasgupta and Verick 2017). However, large decline in rural women's work participation between 2004-2005 and 2011-2012 from these already low levels has come as a surprise, generating a minor industry of researchers trying to identify causes of this decline. Two explanations dominate: (1) Rising household incomes and rising levels of education tend to reduce supply of labour (Mehrotra and Parida 2017). (2) Changes in labour markets have pushed women out of agricultural jobs, and other opportunities have failed to materialize, reducing demands for women's labour (Klasen and Pieters 2015). A third, and somewhat orthogonal, explanation relates to transformations in labour market conditions that may exacerbate measurement errors in labour force participation already noted by a number of scholars (Himanshu 2011; Hirway 2012).

Whether declining rural work participation rates are due to supply or demand constraints has tremendous policy implications. If women withdraw voluntarily in response to rising economic conditions, this may be seen as part and parcel of economic growth, not requiring policy intervention. If women drop out of the workforce due to difficulties in finding employment, it suggests a need to focus on public policies that increase women's employability and job opportunities.

Research in this area has grown in recent years, but most studies tend to rely on a single source of data, National Sample Survey Rounds 61 (2004-2005), 66(2009-2010) and 68(2011-2012). In this paper, we attempt to triangulate the results from NSSO with India Human Development Surveys of 2004-2005 and 2011-2012 to examine the sources of transformation in women's work participation rates. Alongside these popular explanations, we also examine the role played by oft neglected cultural norms in shaping women's response to changing employment conditions, thereby adding to richness of the analysis.

\section{Contours of Transformation in Women's WPR}

Figure 1 presents data on women's work participation from different rounds of NSSO using Usual Status data. It highlights two trends: (1) Although urban women have lower work participation rates (WPR) than rural women, these figures are more or less stable over the past 20 years. Decline in WPR is mainly a rural phenomenon. (2) Rural women's work participation rates (WPR) show considerable fluctuation, with an upswing in WPR in 2004-2005, an aberration from the general downward trend. Himanshu attributes part of this fluctuation in early years to changes in data collection methodology (Himanshu 2011).

\section{Methodological Challenges to Interpreting trends in WPR}

Time-use researchers have long argued that NSSO data do not fully capture women's participation in economic activities (Hirway 2012; Hirway and Jose 2011). They suggest that women's contribution to economy cannot be fully measured because 

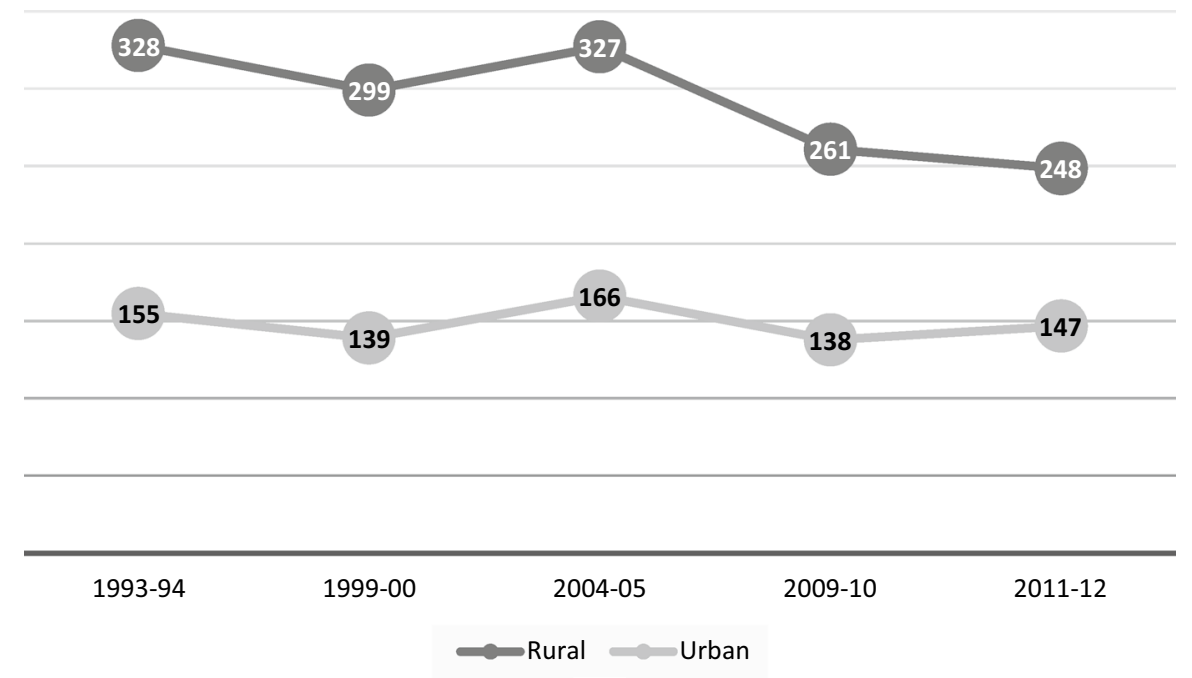

Fig. 1 Trends in women's work participation rates per 1000 women

many women are employed in informal work and survey instruments do not adequately captured informal sector work or self-employment. A large portion of this may be due to women themselves or interviewers discounting women's activities that should be included in economic activities.

An observation from our fieldwork illustrates the challenges. While interviewing in a Gujarat village, we passed a small kirana shop several times a day. A woman was competently handling the shop. It so happened that her household was selected randomly in our sample. While interviewing, she failed to mention the fact that she works in the family shop. When queried about it, she said, "Oh, my husband takes care of the shop. I only work in it when he has to go to the town for buying supplies or for government work." The husband was the Panchayat Pradhan and was absent from the shop 2-3 times a week. Nonetheless, our respondent did not think of herself as working, just "helping", help not worth mentioning in an interview.

Alternative measures of employment calculated based on detailed time-use data reveal tremendous gap by data collection method. Time-use survey of 1998-1999 for Haryana, Madhya Pradesh, Gujarat, Odisha, Tamilnadu and Meghalaya shows that if WPR were to be collected using time-use data, in these six states, $58 \%$ of the rural women would be considered employed, while using the NSSO for 1999-2000, only $25 \%$ fall in this category (Hirway and Jose 2011).

However, we do not fully know whether these cross-sectional differences are stable or whether they vary over time. NSSO is planning to undertake full time-use survey in near future, but until these data are available, it would be hard to know whether measurement errors explain some portion of declining WPRs. However, there are two reasons to believe that this might be the case.

First, getting adequate coverage of women's activities requires substantial training since women themselves often do not report the activities that fall into System 
of National Accounts (SNA). For women respondents and their households, what should be treated as economic activity in survey may often be part and parcel of their domestic duties (e.g. cooking meals for hired farm labourers or milking cows). Interviewers need to be specially trained to ensure that they probe to get good estimates of these activities. Observers note that over time, NSSO interviewer pool has shifted from regular employees to contractors, possibly resulting in poorer data quality (Vaidyanathan 2001).

Second, the nature of work has changed substantially over the past decade. Increasingly women's work has become fragmented and contingent. When women work for 10 days as farm labourers, a few months later 10 days in MGNREGS and during the harvesting season spend 20 days in the family farm, they should be classified as workers under the NSSO subsidiary status definition, but there is a chance that this may fall under the radar if the NSSO interviewers do not probe and simply ask, "did you work for at least 30 days in any economic activity?"

We examine data from the India Human Development Survey of 2004-2005 and 2011-2012 to see how a different questionnaire structure may provide alternative answers. Unlike the NSSO, the IHDS collects data on both income and employment in a single module. Thus, it first asks whether the household owns or cultivates land, then asks about season-wise production and finally asks who engaged in farm work. Interviewers are instructed to ask whether any women or children worked on the farm but may have been omitted. Similarly, for wage and salary work, it lists every single paid activity that individuals undertake, regardless of the number of days they work. This allows for a greater capture of fragmented and multiple activities. As a result, IHDS work participation rates (Table 1) for women are substantially higher than the NSS participation rates, but those for men are comparable.

Moreover, as Table 1 shows, the difference between NSS and IHDS WPR is located largely in work in family enterprises including farm or dairy. In this paper, work participation rate in IHDS is defined by calculating total number of hours women report working on family farm or in family business, in wage labour including agricultural and non-agricultural work. These hours are calculated by multiplying number of days worked in the preceding 12 months times number of hours worked on average. If the total number of hours is more than $240 \mathrm{~h}$ (roughly comparable to NSSO subsidiary status definition), women are counted as being in the workforce. Moreover, if the household owns any livestock and women report regularly taking care of the livestock throughout the year, they are also counted as being in the workforce. This brings the IHDS definition closer that used by NSSO's usual status definition that includes both primary and subsidiary statuses.

Figure $2 \mathrm{a}, \mathrm{b}$ describes changes in the labour market participation of men and women aged 25-64 years between 2004-2005 and 2011-2012. The figures show that if we do not limit ourselves to the NSSO definition of PS and SS and focus on any work, even if it is undertaken discontinuously, spread across different activities and done for a short time, the proportion of population that is not employed drops for women from 54 to $50 \%$, while the proportion of women who work for one or two months increases slightly. This suggests that the NSS criterion of ignoring shortterm work may be missing out some important changes in Indian labour markets, particularly for women. 
Table 1 Work participation rates of rural men and women in 2004-2005 and 2011-2012

\begin{tabular}{|c|c|c|c|c|c|c|}
\hline & \multicolumn{3}{|c|}{ National Sample Survey $^{\mathrm{a}}$} & \multicolumn{3}{|c|}{ India Human Development Survey ${ }^{\mathrm{b}}$} \\
\hline & Any work & $\begin{array}{l}\text { Family- } \\
\text { based work }\end{array}$ & Wage work & Any work & $\begin{array}{l}\text { Family- } \\
\text { based work }\end{array}$ & Wage work \\
\hline \multicolumn{7}{|l|}{ All men } \\
\hline 2004-05 & 54.6 & 38.3 & 26.4 & 54.1 & 36.9 & 24.5 \\
\hline 2011-2012 & 54.3 & 33.1 & 28.0 & 53.4 & 32.4 & 26.6 \\
\hline \multicolumn{7}{|c|}{ Men ages 25-64 } \\
\hline 2004-05 & 96.5 & 68.6 & 46.8 & 91.9 & 61.0 & 44.6 \\
\hline 2011-2012 & 96.1 & 58.9 & 49.6 & 90.0 & 54.7 & 47.0 \\
\hline \multicolumn{7}{|l|}{ All women } \\
\hline 2004-05 & 32.7 & 23.9 & 13.7 & 38.4 & 30.9 & 13.0 \\
\hline 2011-2012 & 24.8 & 15.7 & 11.7 & 36.5 & 27.5 & 13.6 \\
\hline \multicolumn{7}{|c|}{ Women ages $25-64$} \\
\hline 2004-05 & 56.8 & 41.6 & 23.9 & 66.0 & 53.1 & 23.6 \\
\hline 2011-2012 & 42.8 & 26.9 & 20.6 & 63.8 & 48.2 & 24.9 \\
\hline
\end{tabular}

${ }^{a}$ NSS WPR based on Usual Status (US + PS) definition

${ }^{\mathrm{b}}$ IHDS WPR based on whether respondent contributed at least $240 \mathrm{~h}$ total in household farm, business or wage work. Individuals who regularly take care of any livestock are also coded as working

The other reason behind the underestimation of work in the NSS may have to do with fragmentation of work. When individuals work in more than one activity and no activity meets the threshold of 30 days, it is possible that enumerators omit these activities from their activity count. IHDS surveys document a considerable increase in the proportion of men and women who undertake both agricultural and non-agricultural works.

Another clue to possible underestimation of women's work is visible when we examine work participation of men and women by amount of land cultivated by their families (Table 2). NSS records that the number of men and women working in family work increases as farm size increases. However, over time, for any given farm size, the number of men and women working on family farm dropped substantially between 2004-2005 and 2011-2012. Movement away from agriculture and growth of non-farm work has been well documented in the literature, but the extent of decline in individuals working on family farms seems somewhat implausible. NSS data show that in 2004-2005, for farms less than 0.5 hectares, an average farm employed 1.06 men and 0.66 women as family labourers. About $12 \%$ of these farms did not have any single individual who spent at least 30 days working on the farm.

The number of family members working on these small farms dropped significantly between 2004-2005 and 2011-2012 according to NSS data, while proportion of small farms with no family members working on it increased to $25 \%$. A quarter of the small farms with no family input seems highly implausible. In contrast, the IHDS data show only a tiny increase in farms without family labour-from 7.5 to $8.9 \%$. Taken in conjunction with other statistics presented above, it is reasonable to 


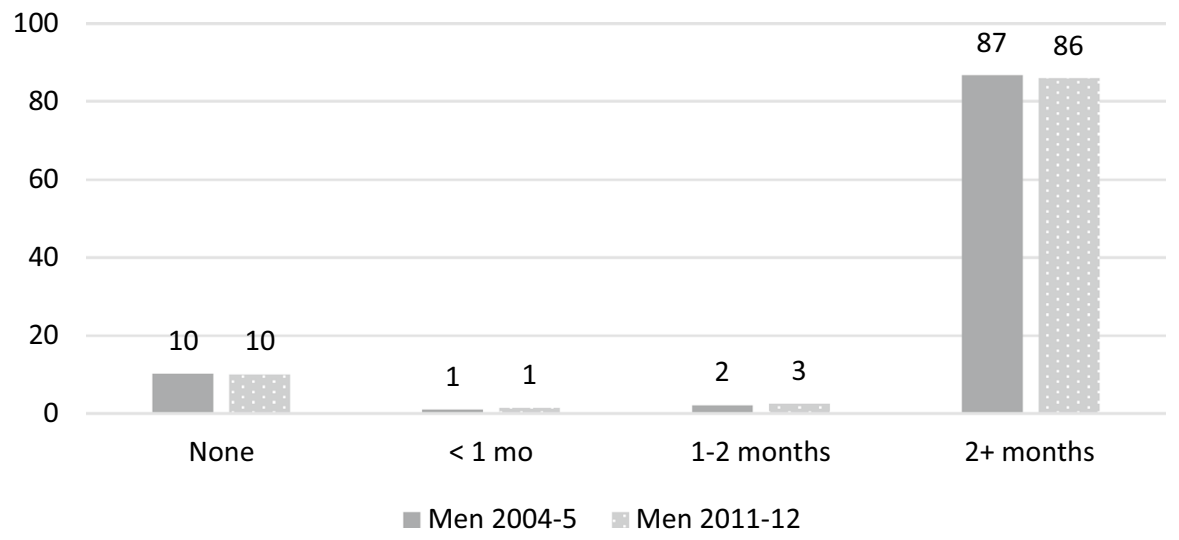

(a)

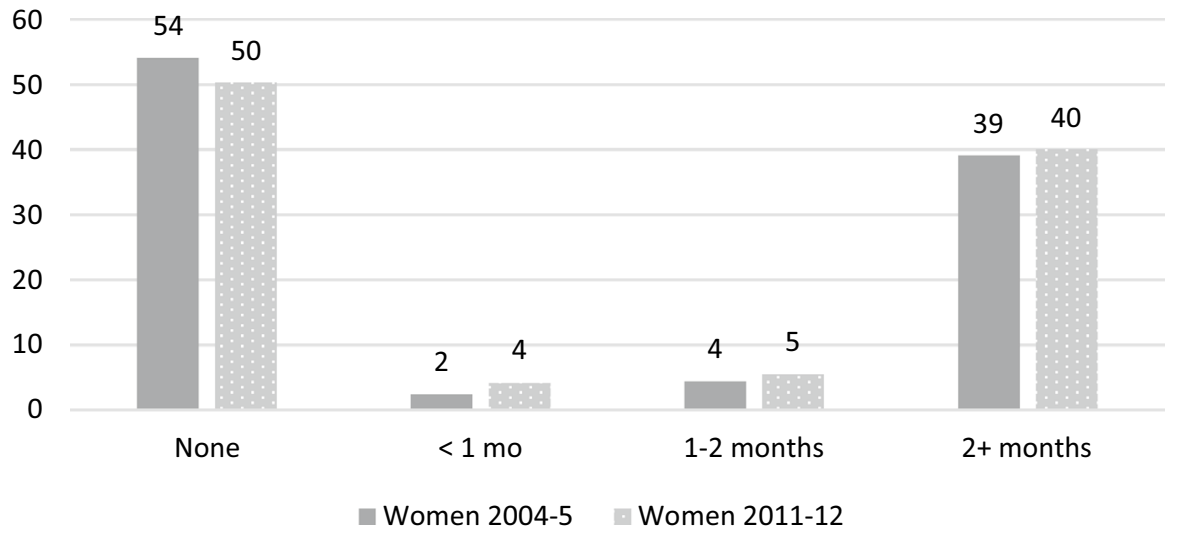

(b)

Fig. 2 a Distribution of days worked men ages 25-64 in 2004-2005 and 2011-2012 (IHDS). b Distribution of days worked women ages 25-64 in 2004-2005 and 2011-2012 (IHDS)

wonder if decline in women's work on family farms might be overestimated and be an artefact of data collection rather than being totally due to secular changes.

Using a different data collection strategy, not only do IHDS data record greater WPRs for rural women than the NSSO data, they also show smaller decline in rural female WPRs between 2004-2005 and 2011-2012. It is important to place IHDS WPRs in context. As noted earlier, the difference in WPR between NSSO and TUS data is nearly twofold. In contrast, in 2004-2005, the IHDS reported somewhat higher WPR than NSSO, but it did not capture the full magnitude of women's work as time-use surveys are able to do.

These observations lead us to suggest that decline in rural women's WPR, as recorded in NSS data, be treated with caution. It is possible that the results from Periodic Labour Force Survey will provide more recent estimates and allow us to 


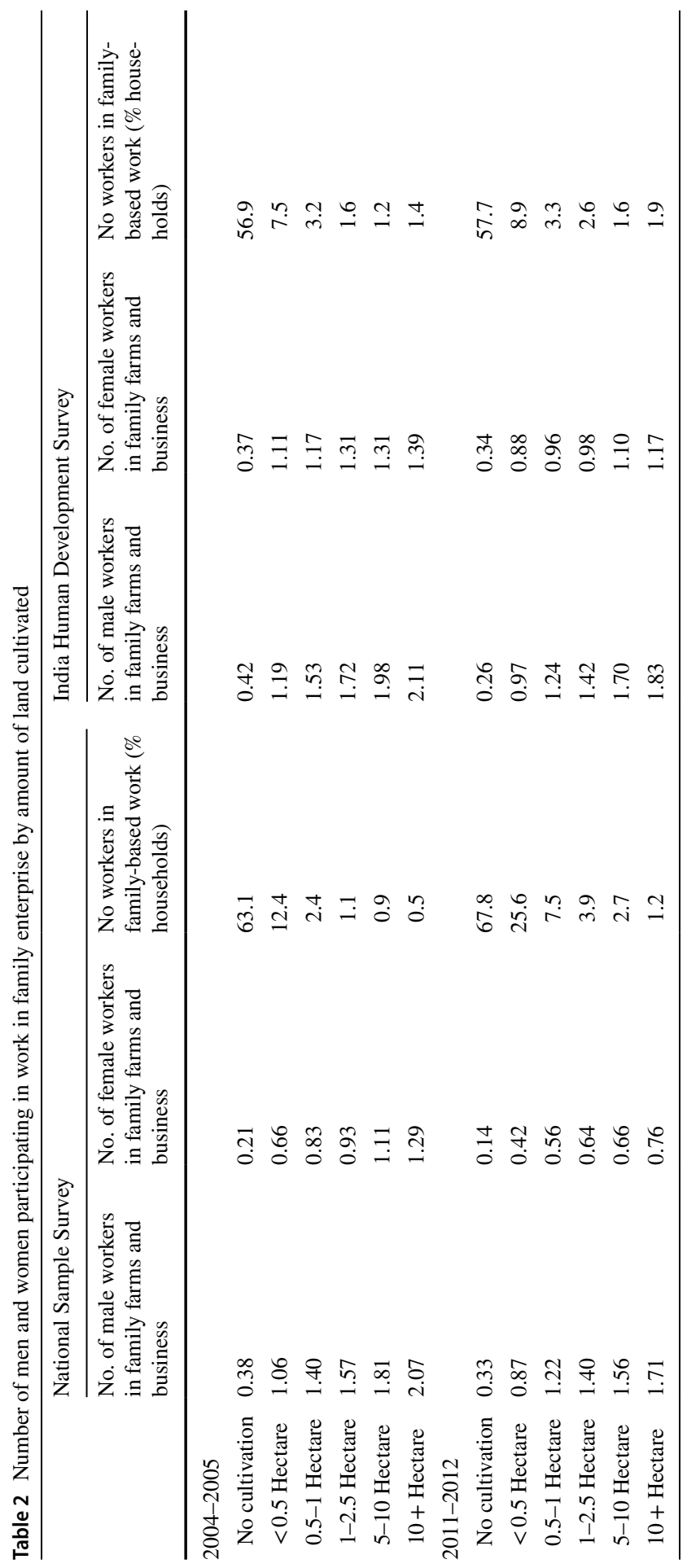




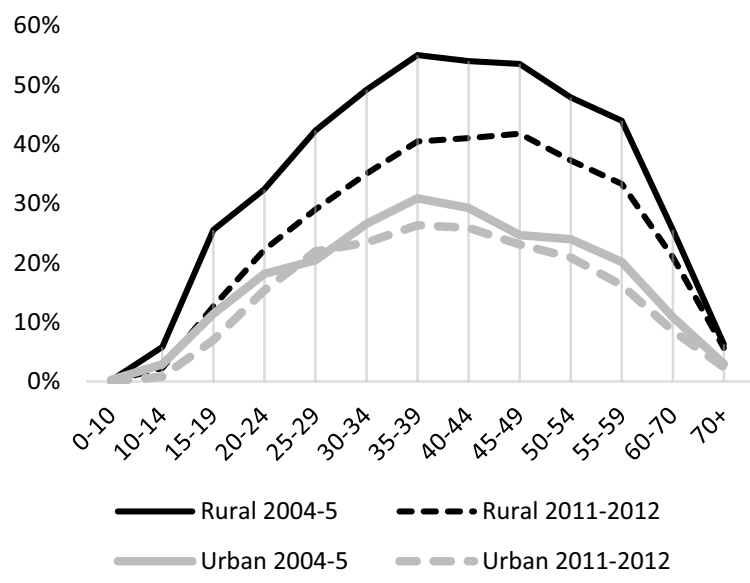

Fig. 3 Changes in work participation rates at different ages for rural and urban women between 20042005 and 2011-2012

better evaluate the results from 68th round of NSSO, but prima facie, it is not possible to rule out the likelihood of measurement error.

\subsection{Rising Education and Withdrawal from Labour Force}

It has been suggested that rising education may explain some of the decline in women's labour force participation (Rangarajan et al. 2011). As young women continue to pursue education, demands on their time may make it difficult for them to continue to participate in the workforce. This is a plausible explanation for decline in WPRs for young women (and men). However, as we look at the NSSO data, it is clear that this decline is not limited to younger workers (Kannan and Raveendran 2012). As Fig. 3 (Desai et al. 2018) documents, women ages 25-59 have also experienced substantial decline in WPR.

This does not mean that current enrolment is the only mechanism through which education may influence labour force participation. In a seminal paper, Arleen Leibowitz argued that education improves women's productivity in educating children (Leibowitz 1974), creating a greater pressure on women's time. Similar arguments have been made for India by Afridi, Dinkelman and Mahajan (2018). Recent studies based on IHDS data show that increased investments in children's education have emerged as a major impetus driving family decisions in India (Basu and Desai 2016) and intense maternal employment has a potential for influencing children's academic performance by reducing their involvement in school-related activities such as supervision of homework and participation in parent-teacher association (Vikram et al. 2018).

However, if this is the explanation for declining women's labour force participation, then we should see an accentuation of the familiar U-shaped curve (Chatterjee et al. 2018) between 2004-2005 and 2011-2012. The data presented in Fig. 3 fail to 


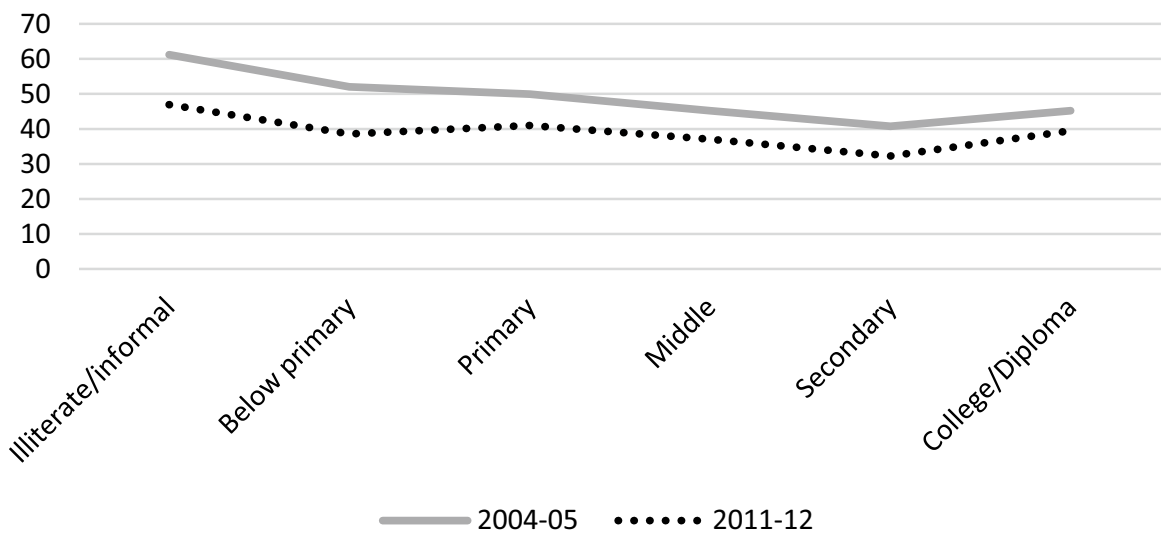

Fig. 4 Work participation by education level for rural women ages 25-64 (NSS)

show this. Much of the decline in rural women's WPR is located at the bottom of the educational distribution. It is women with less than primary education who seem to be dropping out of the workforce rather women with higher education (Fig. 4).

\subsection{Rising Incomes and Withdrawal from the Labour Force}

Incomes have risen steadily, while poverty has fallen between 2004-2005 and 2011-2012. With rising household incomes, household reliance on women's incomes may fall and women and their families may prefer to invest women's time in domestic activities and child care (Neff et al. 2012). This argument is highly plausible if we look at cross-sectional data. At any given point in time, household income is negatively related to women's work participation rates. However, whether this cross-sectional relationship can be extended to explain the decline in women's WPR remains questionable.

As Table 2 shows, much of the decline in women's WPR in NSSO surveys has occurred in households at a lower income level rather than those at a higher income level. Since NSS measure of household income relies on household consumption, which is also a function of women's labour incomes, it is not easy to establish an unambiguous relationship relying solely on NSSO data. Neff et al. (2012) try to work around this by using male wage income; however, selectivity into wage employment for men makes it an imperfect strategy. Since IHDS collects both wage and non-wage income, we calculate household incomes excluding the index woman's own income. In order to do this, we subtract women's wage income from the household income and attribute farm and business incomes to different household members based on their labour contribution to these activities (Table 3).

These descriptive results show that although at any given point in time, women from higher economic status families are less like to work than women from lower income families, a movement along the income ladder does not explain the decline in the WPR reported by NSS. Most of the declines in women's WPR in NSS data are located at the lower levels of incomes. In contrast for IHDS, there seems to be 
Table 3 Changes in work participation at the same levels of consumption/income (NSS and IHDS)

\begin{tabular}{|c|c|c|c|c|c|}
\hline \multicolumn{2}{|c|}{ Any work } & \multicolumn{2}{|c|}{ Family-based work } & \multicolumn{2}{|c|}{ Wage work } \\
\hline 2004-05 & 2011-2012 & 2004-05 & 2011-2012 & 2004-05 & 2011-2012 \\
\hline
\end{tabular}

National Sample Survey

Monthly per capita consumption expenditure in 2011-2012 constant terms

$\begin{array}{lllllll}0 & 60 & 46 & 38 & 26 & 36 & 26 \\ 1-500 & 58 & 41 & 41 & 25 & 28 & 21 \\ 501-1000 & 56 & 45 & 44 & 28 & 19 & 22 \\ 1001-1500 & 55 & 44 & 46 & 30 & 14 & 19 \\ 1501-2000 & 51 & 42 & 42 & 30 & 12 & 16 \\ 2001-2500 & 49 & 42 & 40 & 27 & 11 & 17 \\ 2501+ & 45 & 40 & 33 & 28 & 15 & 15 \\ \text { Total } & 57 & 43 & 42 & 27 & 24 & 21\end{array}$

India Human Development Survey

Monthly per capita income (excluding index woman's contribution) in 2011-2012 constant terms

$\begin{array}{lllllrl}0 \text { or negative } & 76 & 72 & 60 & 54 & 33 & 30 \\ 1-500 & 66 & 66 & 51 & 49 & 25 & 29 \\ 501-1000 & 58 & 64 & 49 & 47 & 16 & 26 \\ 1001-1500 & 49 & 59 & 41 & 43 & 9 & 20 \\ 1501-2000 & 49 & 55 & 42 & 43 & 9 & 16 \\ 2001-2500 & 46 & 54 & 42 & 41 & 4 & 17 \\ 2501+ & 45 & 52 & 41 & 41 & 2 & 10 \\ \text { Total } & 66 & 64 & 53 & 48 & 24 & 25\end{array}$

a slight increase in WPR, particularly in wage work, for women from upper-income households but with whole income distribution moving upwards and a cross-sectional negative relationship between household income and women's work participation, the net effect is very small.

\subsection{Compositional Vs. Secular Changes: Results from Oaxaca-Blinder Decomposition}

Optimistic interpretations of decline in women's work participation rates rely on the assumption that cross-sectional relationships foreshadow longitudinal trends and argue that rising education and incomes may be associated with declining work participation rates for women (Kapsos et al. 2014) (Klasen and Pieters 2012; Neff et al. 2012). However, as we document above, descriptive statistics suggest that while secular changes may be resulting in increases in income and education, the relationship between education and labour force participation and income and labour force participation itself is not stable. Hence, the extent to which compositional changes can explain declines in work participation remains an empirical question. 
Table 4 Oaxaca-Blinder decomposition for any work, family-based work and wage work, women ageing 25-64 (NSS)

\begin{tabular}{lllc}
\hline & Coefficient & SE & $Z$ \\
\hline Any work & & & \\
2004-2005 & 0.568 & 0.002 & 235.52 \\
2011-2012 & 0.428 & 0.004 & 116.27 \\
Difference between two periods & 0.140 & 0.004 & 31.85 \\
Explained (compositional) difference & 0.001 & 0.000 & 4.92 \\
Unexplained (coefficient) difference & 0.139 & 0.005 & 30.5 \\
Family-based work & & & \\
2004-2005 & 0.416 & 0.002 & 170.18 \\
2011-2012 & 0.269 & 0.003 & 80.37 \\
Difference between two periods & 0.147 & 0.004 & 35.43 \\
Explained (compositional) difference & 0.000 & 0.000 & 1.79 \\
Unexplained (coefficient) difference & 0.147 & 0.004 & 35.06 \\
Wage work & & & \\
2004-2005 & 0.239 & 0.002 & 111.87 \\
2011-2012 & 0.206 & 0.003 & 68.18 \\
Difference between two periods & 0.033 & 0.004 & 8.97 \\
Explained (compositional) difference & 0.031 & 0.002 & 12.9 \\
Unexplained (coefficient) difference & 0.003 & 0.002 & 1.27 \\
\hline
\end{tabular}

In order to address it, we estimate Oaxaca-Blinder decomposition models for both NSS and IHDS data. These equations are estimated using STATA V15 with logit link function. The equation for Oaxaca-Blinder decomposition of WPR in 2004-2005 and 2011-2012 is as follows:

Let $y_{i}$ be the WPR, our variable of interest. We have two groups indicating two time periods 2004-2005 and 2011-2012, respectively. Assume that $y_{i}$ is explained by a vector of determinants, $\mathbf{x}$. Therefore,

$$
y_{i}= \begin{cases}\beta^{2004-05} x_{i}+\varepsilon_{i}, & \text { if } i=2004-2005 \\ \beta^{2011-12} x_{i}+\varepsilon_{i}, & \text { if } i=2011-2012\end{cases}
$$

Then the gap in mean WPR for two time periods can be thought of as deriving from the explained (compositional) difference and the unexplained (coefficient) difference (Table 4).

The equation for NSSO data controls for variation in age, education, social group, religion, household size, log of monthly per capita expenditure and state of residence. Results show that compositional changes, particularly those in education and household per capita income, explain only a small proportion of the decline in WPR between 2004-2005 and 2011-2012 for all work and familybased work. However, these factors explained much of the decline in wage work with unexplained variation playing a very small and insignificant role. 
Table 5 Oaxaca-Blinder decomposition for any work, family-based work and wage work, women ageing 25-64 (IHDS)

\begin{tabular}{lrrr}
\hline & Coefficient & SE & Z \\
\hline Any work & & & 156.25 \\
2004-2005 & 0.662 & 0.004 & 157.57 \\
$2011-2012$ & 0.639 & 0.004 & 3.92 \\
Difference between two periods & 0.023 & 0.006 & 9.81 \\
Explained (compositional) difference & 0.023 & 0.002 & -0.03 \\
Unexplained (coefficient) difference & 0.000 & 0.006 & 117.15 \\
Family-based work & & & 116.08 \\
2004-2005 & 0.532 & 0.005 & 7.96 \\
2011-2012 & 0.483 & 0.004 & 4.28 \\
Difference between two periods & 0.049 & 0.006 & 6.63 \\
Explained (compositional) difference & 0.010 & 0.002 & 0.006 \\
Unexplained (coefficient) difference & 0.039 & & 65.18 \\
Wage work & & 0.004 & 68.57 \\
2004-2005 & 0.237 & 0.004 & -2.39 \\
2011-2012 & 0.250 & 0.005 & 11.27 \\
Difference between two periods & -0.012 & 0.002 & -10.04 \\
Explained (compositional) difference & 0.027 & 0.004 & \\
Unexplained (coefficient) difference & -0.040 & & \\
\hline
\end{tabular}

Results for similar Oaxaca-Blinder decomposition using the IHDS data are presented in Table 5. In this analysis, instead of monthly per capita expenditure, we control for log of the monthly per capita income excluding the index woman's own contribution. Other variables included in the regression are age, education, unearned income and an indicator, showing that unearned income is missing or negative, social group, household size and state of residence. Results from the IHDS show a slightly different pattern from that for NSS data. It shows that secular changes explain most of the difference in overall work participation rates, although their explanatory power is lower for family-based work and wage work when treated separately. For wage work, IHDS results are particularly interesting. They suggest that judging by the secular change in income and education, women should reduce their participation in wage and salary work; instead, they seem to be slightly more likely to engage in this work. This may be due to unexplained changes in the economy that changes the relationship between included variables and participation in the wage work.

\subsection{Do Cultural Norms Play a Role in Shaping Household Reactions to Rising Incomes?}

While economic literature has recently begun to focus on role of social norms in shaping women's labour supply decisions (Fletcher et al. 2004) (Neff et al. 2012), 
sociological and anthropological literature has a long history of noting that families and caste groups often gain social status via encouraging women's seclusion (Desai 2017). Noted anthropologist M. N. Srinivas in a seminal paper titled "The Changing Position of Women in India" argued:

The idea is widespread that working for wages is a mark of low status, and landowners... do not work for wages. This is true for both men and women. The women, in particular, find high status incon-sistent with even extra-mural movement, with the result that upward mobility leads to their 'immurement.' (Srinivas 1977, p. 256)

He noted the conflict between modernity and social status gained via physical withdrawal from conditions that may be insulting to women's dignity and suggested that rising incomes may facilitate women's withdrawal from the labour force. Ursula Sharma similarly notes that seclusion often practiced via covering one's face is used as a nod to propriety; poor women have no option but to work even while practicing ghunghat (Sharma 1980).

Social status and women's labour force participation have a complex relationship. Withdrawal from wage labour where women may face conditions exposing them to potential abuse and lead to diminishing the status of their family is seen often as activities to be avoided if financial conditions permit. But at the same time, work on family farm is seen as being less damaging. Moreover, a white-collar governmental job is perceived as a job that brings a status to the family that may make up for any status loss due to wage employment.

In order to examine the role of social norms in shaping responses to rising income, we take advantage of the panel structure of India Human Development Survey and estimate a series of within household fixed-effects models. This analysis focuses on women who live in households that were interviewed in both 2004-2005 and 2011-2012 and contained at least one ever-married woman ages 15 to 49 who responded to questions regarding gender norms. This provides us with a sample of 28,260 women for 2004-2005 and 37,845 women for 2011-2012. While IHDS data contain a variety of indicators for gender relations in the household, we focus on a single marker of gender norms, whether women habitually cover their face by relying on ghunghat or purdah. Both ghunghat and purdah vary in their intensity across length and breadth of India (Desai et al. 2010). Women in Haryana tend to fully cover their face, and women in Gujarat pull over their sari over their faces when needed to show deference to elder men in the vicinity. But in either case, by responding affirmatively to practicing ghunghat or purdah, we assume that they are cognizant of the need to practice seclusion under certain conditions.

We estimate the impact of changes in log of unearned income on changes in women's work participation using household-level fixed-effects models. These models are estimated for the full sample as well as the two subsamples-one in which women cover their faces and the other in which they do not. In this analysis, we control for changing household conditions for women which include their age, number of children living with them, marital status and log of household income (excluding their own contribution).

The household fixed-effects equation is as follows: 
Table 6 Variation in impact of log of family income (excluding index woman's own contribution) across different normative contexts

\begin{tabular}{llll}
\hline & All women & $\begin{array}{l}\text { Practice } \\
\text { Ghunghat/ } \\
\text { Purdah } \\
\text { Coefficient }\end{array}$ & $\begin{array}{l}\text { Do not practice } \\
\text { Chunghat/Purdah }\end{array}$ \\
\hline Any work & $-0.301 * * *$ & $-0.288^{* * *}$ & $-0.325 * * *$ \\
Family-based work & $-0.088^{* * * *}$ & $-0.047 * * *$ & $-0.130 * * *$ \\
Wage work & $-0.298^{* * *}$ & $-0.424 * * *$ & $-0.206 * * *$ \\
\hline$* p<=0.05 . * * p<=0.01 * * * p<=0.001$ & \\
& & \\
\multicolumn{1}{c}{$y_{i t}=\ddot{X}_{i t} \beta+\ddot{u}_{i t}$} &
\end{tabular}

where $\ddot{X}_{i t}$ is the demeaned time-variant regressor matrix and $\ddot{u}_{i t}$ is the error matrix.

Results, presented in Table 6, provide an interesting insight into the role of social norms. They show that overall, rising household incomes reduce all women's work participation; however, contrary to our expectations, the negative impact is stronger for women in more relaxed gender contexts than for women in more conservative contexts. When we separate the impact of income on work participation by wage work and family work, we find that here the results are consistent with our expectations. Rising incomes reduce women's participation in wage work, and this impact is substantially larger for more conservative gender contexts. In contrast, impact of rising incomes on women's family-based work is relatively small in more conservative contexts but substantially larger in more liberal context, possibly because in these contexts rising incomes may allow women to build on their social networks to gain higher-status market-based work.

These results indicate the need to undertake a nuanced analysis when exploring the role of social norms in shaping women's labour market behaviours.

\section{Role of Public Policies in Expanding Women's Employment Opportunities}

Results presented above suggest that while rising incomes play some role in reducing women's labour supply, changes in women's labour market behaviours are not fully explained by the rising supply; lack of work opportunities may play an important role in keeping women out of workforce.

Both the NSS and IHDS record a great willingness to work on the part of women currently not employed. NSS data from 2011 to 2012, reported by Fletcher et al. (2018), reveal that more than $30 \%$ of the women engaged in domestic duties would like to work. IHDS data show that $65 \%$ of women who are not currently working would like to work if they could find suitable work. Almost all these women also reported that their families would be willing to let them work. However, expressing a willingness to work to an interviewer is quite different from actually accepting work when it becomes available. 


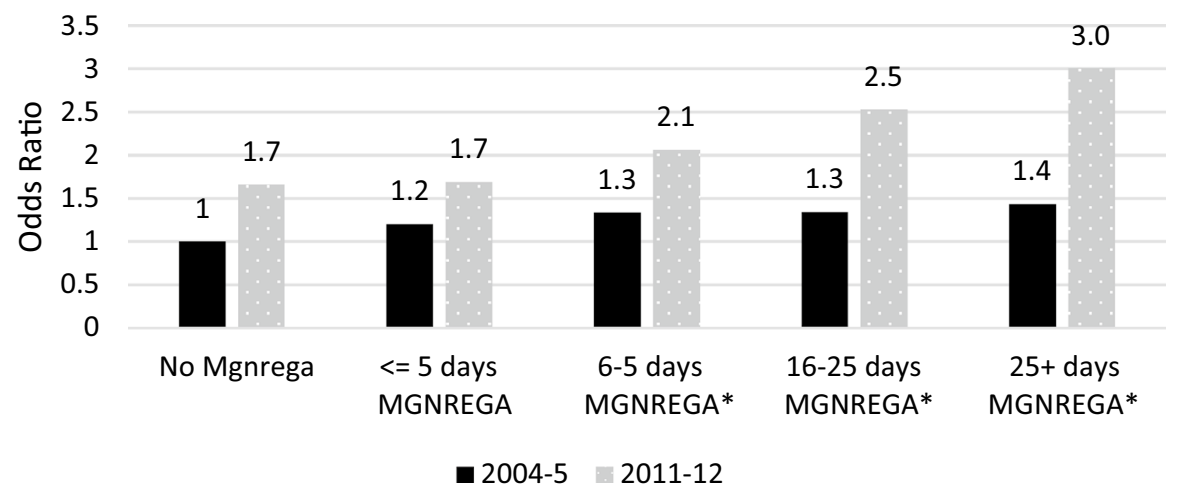

Fig. 5 Increase in odds of undertaking wage work by MGNREGA work availability between 2004-2005 and 2011-2012

Two analyses based on IHDS document that women expand their labour market participation and engage in non-farm work when such work is available. The first study examines the role of improvements in transportation networks to estimate the impact of improved transportation on women's participation in non-farm work (Lei et al., forthcoming). Using person-specific fixed-effects models, this study finds that women are more likely than men to respond to improved transportation networks, although this effect is conditional on gender norms. Women living in more egalitarian communities respond to improved transportation and take up non-farm jobs in nearby towns.

The second study (Desai 2018) examines the impact of introduction of Mahatma Gandhi National Rural Employment Guarantee Scheme (MGNREGS) on men's and women's work participation rates within each village. It finds that in villages which implemented MGNREGS more vigorously and provided larger amount of work opportunities, women increased their participation in wage work substantially. While men seem to use MGNREGS work to replace other work, for women this is a net gain, bringing many women in paid work who used to work solely on family farms and in family business before the introduction of MGNREGS (Fig. 5).

\section{Conclusions}

The apparently declining WPR for rural women between 2004-2005 and 2011-2012 has set up a ferocious debate regarding whether this is due to rising prosperity that leads to women's labour force withdrawal or jobless growth that has pushed women out of labour force.

The analysis presented in this paper suggests three observations:

First, while it is premature to conclude that measurement error lies behind the large decline in rural women's work participation rates recorded by National Sample Surveys, there is sufficient evidence to suggest that possibility of measurement 
error should not be ruled out. Changes in labour market conditions may have led to discontinuous and fragmented work that may not be easy to capture in NSS surveys. Decline in women's work participation for households with very small farms is indicative of the type of work that may be easy to miss out.

Second, rising incomes are associated with lower levels of labour force participation. Although cross-sectional findings from NSS do not lend themselves well to longitudinal predictions, panel data from IHDS show that rising incomes are associated with lower levels of work participation. However, the way in which these relationships operate depends on type of work under study and the nature of gender norms and community context.

Third, results based on IHDS also show that when work opportunities expand, e.g. via improvement in transportation networks and increase work opportunities via MGNREGS, women seem to respond by increasing their participation in wage work.

This suggests that the apparent decline in WPR for rural women may be associated with the crowding out of women in agriculture where land fragmentation has led to a reduction in both the size of farms and the demand for labour, be it household members or agricultural labourers. The decline in female employment is mostly reported for the least educated and poorest women. In areas where alternative job opportunities become available to women, either through public works programmes or through their increased ability to commute to nearby towns and larger villages, women's participation in paid work seems to increase. Hence, in order to reap the gender dividend, India needs to focus on augmenting women's economic participation by not only facilitating creation of new jobs for women but also offering them greater access to existing jobs. Only sustained efforts in these areas can help India combat its alarmingly low female WPRs and ensure an equitable gendered distribution of work.

Acknowledgement This work was supported by grants OPP1187930 and OPP1183495 from Bill and Melinda Gates Foundation.

Open Access This article is distributed under the terms of the Creative Commons Attribution 4.0 International License (http://creativecommons.org/licenses/by/4.0/), which permits unrestricted use, distribution, and reproduction in any medium, provided you give appropriate credit to the original author(s) and the source, provide a link to the Creative Commons license, and indicate if changes were made.

\section{References}

Afridi, F., T. Dinkelman, and K. Mahajan. 2018. Why are fewer married women joining the work force in india? Journal of Population Economics, 31(3):783-818.

Basu, A.M., and S. Desai. 2016. Hopes, dreams and anxieties: India's one-child families. Asian Population Studies 12(1): 4-27. https://doi.org/10.1080/17441730.2016.1144354.

Chatterjee, E., S. Desai, and R. Vanneman. 2018. Indian paradox: Rising education, declining womens' employment. Demographic Research 38: 856-875.

Dasgupta, S., and S.S. Verick (eds.). 2017. Transformation of women at work in Asia: An unfinished development agenda. Los Angeles: Sage.

Desai, S., N. Deshmukh, and B. Chouhan. 2018. Supply or demand: What accounts for declining female work participation in rural India?. New Delhi: National Council for Applied Economic Research National Data Innovation Centre, Data Brief 1. 
Desai, S. 2017. Doing gender vs. doing modernity: The dilemma of Indian middle Classes. In Locating gender in the new middle classes, ed. M. Bhatia, 77-98. Shimla: Indian Institute of Advanced Study.

Desai, S. 2018. Do public works programs increase women's economic empowerment: Evidence from rural India. India Human Development Survey working paper 2018-02. Retrieved from. https://ihds. umd.edu/sites/ihds.umd.edu/files/MGNREGA\%20\%26\%20Women\%27s\%20Econ\%20Empowerm ent_Oct\%202018.pdf. Accessed 15 Dec 2018.

Desai, S., A. Dubey, B.L. Joshi, M. Sen, A. Shariff, and R. Vanneman. 2010. Human development in India: Challenges for a society in transition. New Delhi: Oxford University Press.

Fletcher, A.C., L. Steinberg, and M. Williams-Wheeler. 2004. Parental influences on adolescent problem behavior: Revisiting Stattin and Kerr. Child Development 75(3): 781-796. https://doi.org/10.11 11/j.1467-8624.2004.00706.x.

Fletcher, E., R. Pande and C. Moore 2018. Women and work in India: Descriptive evidence and a review of potential policies, faculty research working paper series. RWP18-004. Retrieved from: https:// www.hks.harvard.edu/publications/women-and-work-india-descriptive-evidence-and-reviewpote ntial-policies.

Himanshu. 2011. Employment trends in India: A re-examination. Economic and Political Weekly 46(37): 43-59.

Hirway, I. 2012. Missing labour force: An explanation. Economic and Political Weekly 47(37): 67-71.

Hirway, I., and S. Jose. 2011. Understanding women's work using time-use statistics: The case of India. Feminist Economics 17(4): 67-92. https://doi.org/10.1080/13545701.2011.622289.

Kannan, K.P., and G. Raveendran. 2012. Counting and profiling the missing labour force. Economic \& Political Weekly 47(06): 77-80.

Kapsos, S., S. Silberman, and E. Bourmpala. 2014. Why is female labour force participation declining so sharply in India, ILO Research Paper No. 10., Geneva. Retrieved from: http://ilo.ch/wcmsp5/groups/ public/---dgreports/---inst/documents/publication/wcms_250977.pdf.

Klasen, S., and J. Pieters. 2012. Push or pull? Drivers of female labor force participation during India's economic boom. IZA discussion paper. IZA. Retrieved from: https://www.iza.org/publications/ dp/6395/push-or-pull-drivers-of-female-labor-force-participation-during-indiaseconomic-boom.

Klasen, S., and J. Pieters. 2015. What explains the stagnation of female labor force participation in urban India? World Bank Economic Review, 29(3), 449-478. https://doi.org/10.1093/wber/lhv003.

Lei, L., S. Desai, and R. Vanneman. Forthcoming. Village transportation infrastructure and women's nonagricultural employment in India: The conditioning role of community gender context. Feminist Economics.

Leibowitz, A. 1974. Home investments in children. Journal of Political Economy 82(2): S111-S131.

Mehrotra, S., and J.K. Parida. 2017. Why is labour force participation of women declining in India? World Development 98: 360-380.

Neff, D., K. Sen, and V. Kling. 2012. The puzzling decline in rural women's labor force participation in India: A reexamination. GIGA working papers. German Institute of Global and Area Studies. Retrieved from https://www.giga-hamburg.de/de/system/files/publications/wp196_neff-sen-kling .pdf. Accessed 15 Dec 2018.

Rangarajan, C., P.I. Kaul, and Seema. 2011. Where is the missing labour force? Economic and Political Weekly 46(39): 68-72.

Sharma, U. 1980. Women, work and property in North-West India. New York: Tavistock.

Srinivas, M.N. 1977. The changing position of Indian women. Man 12(2): 221-238.

Vaidyanathan, A. 2001. Quality, reliability of NSS data at stake. The Hindu. Retrieved from https://www. thehindu.com/2001/04/19/stories/0619000k.htm. Accessed 15 Dec 2018.

Vikram, K., F. Chen, and S. Desai. 2018. Mothers' work patterns and children's cognitive achievement: Evidence from the India Human Development Survey. Social Science Research 72: 207-224.

Publisher's Note Springer Nature remains neutral with regard to jurisdictional claims in published maps and institutional affiliations. 